té lo sucedido; los mafiosos, al verme en su compañia, huyeron despavoridos. Luego, desperté y no recuerdo más.

Oído el sueño de José y el relato de las enfermeras de la noche, fui encajando las piezas como en un rompecabezas; quizá lo que él vio y sintió eran realidades que le sucedieron, pero alteradas por su mente, influido probablemente por la muerte de su hermana, presenció entierros donde no los había, al igual que don Quijote creyó ver gigantes en lugar de los molinos, o creyó que sus amigos eran sus enemigos, como ejércitos en vez de ovejas...

Ninguno de nosotros ni los compañeros de otros turnos fueron capaces de decirle a José ni a sus parientes lo que en realidad había sucedido. No podíamos hacerle éso a un hombre tan serio y correcto; sin acordar nada entre nosotros, reaccionamos al unísono, formando una piña en pensamiento y modo de actuar.

Sabíamos que José, por su carácter, se «hubiese muerto» de vergüenza si supiese lo que hizo realmente. Formaba ya parte de nuestra gran «familia hospitalaria» y queríamos que guardase un grato recuerdo de su estancia entre nosotros; que tan sólo almacenase en su memoria nuestra amistad y trabajo profesional hacia él y que olvidase los malos ratos pasados,

Los días pasaron y José evolucionó satisfactoriamente, se encontraba físicamente bien y muy animado.

-Buenos días José.

-Buenos días; doctor.

-Vengo a comunicarle que le voy a dar el alta, cuando realice su informe podrá ser trasladado a planta. $\mathrm{Ha}$ evolucionado muy bien.

El médico, con una palmada en el hombro se despidió de él.

-Adiós José.

-Adiós doctor, gracias por todo.

Cuando me fue comunicada por el médico su decisión entré a ver al paciente.

- ¿Cómo te encuentras?

-Ah, muy bien; sabe, me han dado el alta.

-Sí, lo sé, dentro de poco vendrá el celador, te cambiaremos de cama y podrás subir a la planta. Allí podrás estar con tu familia, caminar por los pasillos, hablar con tus compañeros de habitación, jugar a las cartas...

-Les recordaré siempre, han sido ustedes maravillosos, me han hecho sentirme como en mi casa y aunque estaré con mis familiares les echaré de menos.

El momento llegó, mientras el celador se disponía a llevarse a José nos pusimos a su alrededor para despedirle como se merecía, deseándole un pronto restablecimiento y como «broche» le di un beso y apretón de manos.

\section{LA EXPERIENCIA QUE MARCÓ MI VIDA*}

(MARGARITA LOZANO CARRATALÁ)

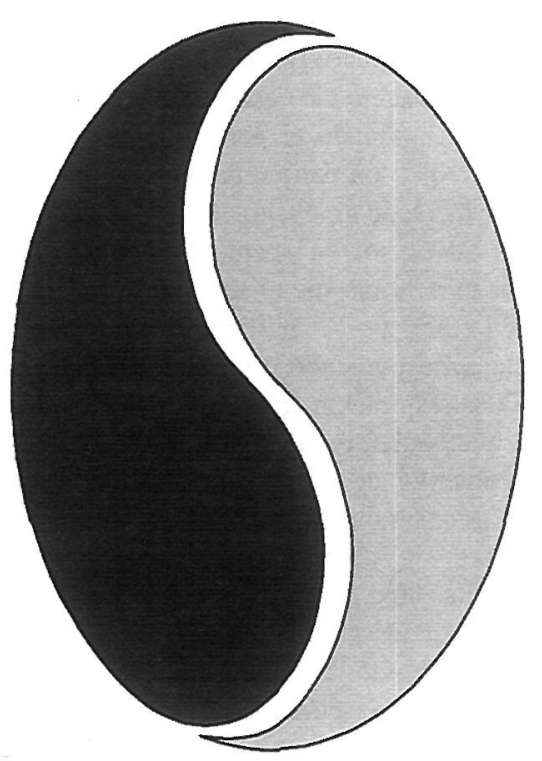

$\mathrm{N}$ unca me había preocupado de prevenir toda la amplia gama de enfermedades que hoy en día existen, tanto las provocadas por mí como las que pudiera contraer. Supongo que sería debido a mis creencias por lo que sentí esa especie de protección. Pero ahora, gracias a una experiencia que viví, sé cómo debo tratar, cuidar y respetar a mi cuerpo.

Un día fui al médico porque desde hacía tiempo no me sentía demasiado bien, ya que tenía molestias y dólores de abdomen después de hartarme a comer. Al principio la cosa no me pareció muy importante, porque no eran unos dolores ni muy aparatosos ni muy significativos. Eran soportables, pero llegó un momento en que lle-

* La autora de este cuento - presentado al II Premio de Narrativa «Vida y Salud»- es estudiante de enfermería y narra en el mismo un hecho tan crucial que llegó a cambiarle por completo la vida. Sin embargo, nada hacía pensar que algo tan trascendente como lo descrito en su su obra estaba a punto de ocurrirle en la vida real. Un accidente de tráfico la llevó a vivir una experiencia vital, una lucha por la vida en cuyo transcurso, tanto su alegría por todo lo que la rodeaba como su alto sentido de la solidaridad contribuirían decisivamente para que, finalmente, ganara la batalla. 
garon a ser irritantes. El doctor, después de hacerme una serie de pruebas, me diagnosticó un cáncer de colon, así que me recomendó, por el grado de desarrollo que presentaba, que siguiera mi vida habitual (incluso que mantuviera invariables mi poco recomendable dieta), ya que me quedaban pocos meses de vida y no había nada que hacer por mucho que me pusiera a aquellas alturas a cuidar de un cuerpo que se me iba por momentos.

Casi sin creérmelo, porque nunca se me había presentado una situación tan desmoralizante, intenté salir de mi confusión buscando el por qué en mi interior. Para ello me marché a un parque natural cerca de mi localidad, donde había un gran lago. En el transcurso de una de esas tardes de reflexión «natural y ecológica», sentada sobre una roca se me fue el santo al cielo y me pilló la noche; sin embargo, no me dejé atrapar por el miedo y logré relajarme poniendo en práctica unas técnicas de control de la respiración, que alguien me había enseñado hacía ya mucho tiempo. Después de varios minutos conseguí mi objetivo, de manera que no sentía mi cuerpo, y mi mente estaba tranquila... tan tranquila como aquel lago. Entonces, sin saber muy bien cómo ni por qué, empecé a musitar algo raro hablándome a mí misma, bajo, muy bajito, como si estuviera rezando. Estuve así durante mucho tiempo, creo que durante horas; pero fue satisfactorio, porque pude llegar a un estado en el que nunca me había encontrado antes, un estado sagrado, casi divino.

De repente empecé a vislumbrar el paisaje exterior, sentí como se me aparecían seres luminosos que se comunicaron conmigo telepáticamente para decirme que querían ayudarme. Me sacaron de mi cuerpo y cada vez lo veía todo más y más grande. Me habían reducido al tamaño de una macropartícula. Nos adentramos en mi organismo por la nariz, pasando por todo el tubo digestivo, hasta llegar a la zona afectada por el cáncer que se divisaba desde lejos como una gran úlcera. Allí, delante mismo del tejido dañado, me comenzaron a explicar cuáles habían sido las razones por las que había llegado a enfermar por culpa de mi ignorancia de los misterios de la vida. Entonces comprendí que yo era la culpable de todo: yo había provocado aquella atrocidad.

En cuestión de segundos, me desperté y volví a sentirme como se siente alguien de este mundo, e intenté recordar todo lo que me habían dicho sobre lo que yo consideraba más importante de la cuestión: la causa y la solución. Sobre la causa me dijeron: «Lo que siembres recogerás». Y sobre la solución: «Haz buenas obras para pagar tus deudas».

Después de esta experiencia nocturna a las orillas del lago, aún medio adormilada, me dirigí a mi casa y allí estuve reflexionando sobre lo ocurrido durante varios días.
Finalmente llegué a una conclusión: debía cambiar mi actitud de despreocupación ante la enfermedad e intentar comprender el funcionamiento de la máquina humana. A pesar de esto, sentía cierta insatisfacción porque no sabía como afrontar la otra recomendación..., la de las buenas obras. Poco después se me presentó una oportunidad que me ayudó a tomar una decisión: en un anuncio de periódico, leí que necesitaban voluntarios que tuvieran valor, además de unos conocimientos básicos en primeros auxilios, para ir a un país africano, uno de esos en los que anida la miseria y que son la síntesis del tercermundismo.

En aquel instante comprendí que iba a ser una gran renuncia, por mi parte, de todo lo que tenía: familia, amigos, trabajo, comodidades de todo tipo; pero creí que era preciso que lo hiciera, ya no sólo por seguir las consignas de aquel extraño sueño y salvar así mi pellejo ayudando a los demás, sino también porque sentía cómo crecía en mí una fuerza que me decía que era necesario ayudar a estas personas necesitadas desde cerca, cara a cara.

Después de mucho papeleo conseguí que me aceptaran y me embarqué para Zaire. Ya sólo me faltaban cuatro meses para el día en el que, teóricamente, debía llegar mi fin, pero yo, con muchísima ilusión, comencé a trabajar como si me quedara toda la vida. Era muy duro ver lo que se veía allí, pero el tener conciencia de que yo hacía lo que estaba a mi alcance para que aquellas personas mejoraran, convertía en algo fascinante el poco tiempo que me quedaba. Un día me di cuenta de que se habían pasado los cuatro meses que me quedaban, aquéllos que los médicos me habían dicho que serían los últimos de mi vida, pero no me alegré demasiado porque pensé que podían haber errado el cálculo por unos días o, a lo sumo, alguna semana y el fin, de forma inevitable, estaría rondándome. Aunque seguía trabajando con el corazón, también sufría por tener que dejar un día no muy lejano todo aquello que había conseguido. Me encontraba dando ánimos para seguir luchando por la vida cuando me estaba muriendo por dentro. ¡Era una situación de locos!

Pasaron unos meses y, una mañana, tal vez por el cansancio acumulado, volví a adormilarme cayendo en aquella especie de estado divino, aunque en aquella ocasión los seres luminosos me comunicaban algo muy distinto. Me dijeron que ya había saldado mi deuda y que por tanto estaba libre de la enfermedad. Sí, aún se me eriza la piel cuando recuerdo cómo me desperté aquella mañana. Estaba tan alegre que lo primero que se me pasó por la cabeza fue preguntarme que qué hacía yo en aquel lugar si, en definitiva, ya había alcanzado mi objetivo: estaba limpia y todo el futuro volvía a ser mío. Pero inmediatamente comprendí que me habían enviado a Zaire a realizar una misión que no la podía hacer nadie más: era mi misión. 